\title{
Cyclo-oxygenase-2 inhibitors or nonselective NSAIDs plus gastroprotective agents: what to prescribe in daily clinical practice?
}

\author{
Gwen MC Masclee ${ }^{1,2}$, Vera E Valkhoff ${ }^{1,2}$, Eva M van Soest ${ }^{1}$, René Schade ${ }^{1}$, Giampiero \\ Mazzaglia $^{3}$, Mariam Molokhia ${ }^{4}$, Gianluca Trifirò ${ }^{1,5}$, Jay L Goldstein ${ }^{6}$, Sonia Hernández- \\ Díaz $^{7}$, Ernst J Kuipers ${ }^{2,8}$, and Miriam C J M Sturkenboom ${ }^{1,9}$
}

${ }^{1}$ Department of Medical Informatics, Erasmus University Medical Centre, Rotterdam, The Netherlands. ${ }^{2}$ Department of Gastroenterology and Hepatology, Erasmus University Medical Centre, Rotterdam, The Netherlands. ${ }^{3}$ Health Search, Italian College of General Practitioners, Florence, Italy. ${ }^{4}$ Primary Care \& Public Health Sciences, Kings College London, London, United Kingdom. ${ }^{5}$ Department of Clinical and Experimental Medicine and Pharmacology, University of Messina, Italy. ${ }^{6}$ Department of Medicine, Division of Gastroenterology, NorthShore University HealthSystem, Evanston, Illinois, USA. ${ }^{7}$ Department of Epidemiology, Harvard School of Public Health, Boston, USA. ${ }^{8}$ Department of Internal Medicine, Erasmus University Medical Centre, Rotterdam, The Netherlands. ${ }^{9}$ Department of Epidemiology, Erasmus University Medical Centre, Rotterdam, The Netherlands.

\section{Summary}

Background-Two strategies for prevention of upper gastrointestinal (UGI) events for nonselective (ns)NSAID users are replacement of the nsNSAID by a cyclo-oxygenase-2-selective inhibitor (coxib) or co-prescription of a gastroprotective agent (GPA).

\begin{abstract}
Aim-To identify whether and in whom either of these strategies should be preferred in daily practice.

Methods-A nested case-control study was conducted using three European primary care databases. We selected a cohort including all naive nsNSAID+GPA ( $\geq 80 \%$ GPA adherence) and coxib users (without GPA use) aged 250 years. Cases with an UGI event (i.e. symptomatic UGI ulcer or bleeding (UGIB) were matched to cohort members without an UGI event on age, sex and number of individual UGI risk factors (i.e. UGI event history, age $\ 65$ years, concomitant use of anticoagulants, antiplatelets, or glucocorticoids) and calendar time. Conditional logistic regression analysis was used to calculate odds ratios (ORs) with $95 \%$ confidence intervals (CI), while adjusting for potential confounders.
\end{abstract}

Results-Within the NSAID cohort ( $\mathrm{n}=617,220), 398$ UGI cases were identified. The risk of UGI events was equivalent for coxib and nsNSAID+GPA ( $280 \%$ adherence) users (OR: 1.02; 95\% CI:0.77-1.37). In concurrent glucocorticoid users, the risk of UGI events was significantly elevated for nsNSAID+GPA ( $\geq 80 \%$ adherence) compared to coxib users (OR: $9.01 ; 95 \%$ CI: 1.61-50.50).

Conclusions-The risk of UGI events was similar in nsNSAID+GPA ( $₫ 80 \%$ adherence) and coxibs users. In patients concurrently using glucocorticoids a significant increase in the risk of UGI events for nsNSAID+GPA users was observed and coxibs should be preferred. 


\section{Keywords}

Cyclo-oxygenase-2 inhibitors; non-selective nonsteroidal anti-inflammatory drugs; symptomatic

UGI events; gastroprotection

\section{Introduction}

Non-steroidal anti-inflammatory drugs (NSAIDs) are frequently prescribed by both general practitioners and medical specialists, and serve as key pharmacological agents in the management of arthralgic and inflammatory conditions. Multiple epidemiologic studies and prospective clinical outcome trials have characterized the risk of NSAID-related gastrointestinal (GI) complications, which include upper gastrointestinal (UGI) ulcers and bleeding. To mitigate the increased risk among long term NSAID users, guidelines have been developed and strategies are recommended ${ }^{1-4}$ including prescription of cyclooxygenase (COX)-2-selective inhibitors (coxibs) or concurrent use of gastroprotective agents (GPAs), such as proton pump inhibitors (PPIs). Although both preventive strategies aim to reduce the incidence of UGI events, the risk of such complications is not eliminated; a considerable proportion of NSAID plus GPA users (6.3-8.5\%) and coxib users (3.7-8.9\%) continues to experience UGI events. ${ }^{5-8}$ Defining which of the two preventive strategies is preferred in terms of UGI safety has been the scope of recent studies. Most of the randomized clinical trials showed no superiority for one of the preventive strategies over the other. ${ }^{5-7,9}$ Only one large randomized clinical trial showed a beneficial effect in favor of celecoxib. In this 6 month trial patients randomized to celecoxib, as compared to the combination of diclofenac and omeprazole, had a reduced rate of clinically significant overall gastrointestinal events when a composite endpoint was considered (events from both the upper and lower GI tract). Looking at the upper gastrointestinal tract specifically, this head to head comparison demonstrated similar rates for upper gastrointestinal bleeding. ${ }^{10}$ Extrapolation of the previously described body of literature to guide clinicians in the care of the general population has several limitations. Many of the prospective randomized clinical studies have included patients using supra-therapeutic doses of coxibs or included a selected group of high-risk patients (i.e. those with a recent UGI event). ${ }^{5-7,10}$ Alternatively in some of the prospective trials, the presence of co-morbid diseases such as ischemic heart disease, peripheral arterial disease ${ }^{10}$, or congestive heart failure ${ }^{5}$ were considered as exclusion criterion, thereby preferentially selecting patients at lower risk of UGI events. Additionally, the exclusion of patients with frequently used co-medication (e.g. low-dose aspirin ${ }^{5}$, anticoagulant agents ${ }^{5,7}$ and corticosteroids ${ }^{7}$ ) in some of the studies might be an important issue, considering that the use of low-dose aspirin clearly influences the efficacy of UGI protection in coxibs. ${ }^{11-12}$ Finally, as a consequence of protocol driven inclusion of patients with recent or past UGI bleeding and in some studies, the recruitment of patients from hospital-setting ${ }^{5,10}$ or endoscopy centers ${ }^{6-7}$, a substantial number of enrolled subjects may have had NSAID-associated complications and as such a higher risk.

Apart from the clinical studies, one population-based cohort study concluded that coxibs alone were not superior to nsNSAID combined with PPI in the prevention of hospitalization for a perforated or bleeding ulcer. ${ }^{13}$ This observation was confirmed in an observational case-control study, using a population-based claims-database in Canada, in which both gastroprotective strategies were similarly effective in the prevention of NSAID-related UGI events, but it did not address the lack of adherence to PPIs. ${ }^{14}$ However, we and others have demonstrated that in real life, GPA adherence during nsNSAID use is an important factor to consider when evaluating and comparing the effectiveness of different gastroprotective strategies. If the NSAID and PPI are given as separate medications non- or low adherence to 
GPAs is often seen ${ }^{15}$ and associated with significantly increased risk of nsNSAID-related upper GI events. ${ }^{16-18}$

Thus, whether coxibs and nsNSAIDs plus GPA are similarly effective in preventing incident NSAID-related UGI events in daily clinical practice including patients both at high- and low-risk is still unknown. Therefore, we conducted a case-control study to compare the risk of UGI events between coxib users and nsNSAID users, who were highly GPA adherent (at least $80 \%$ adherence to GPAs), making use of population-based primary health care data from three European countries. As coxibs might be preferentially prescribed to specific patient groups, we restricted to nsNSAID users who were highly GPA adherent (at least $80 \%$ adherence to GPAs).

\section{Materials and Methods}

\section{Description of data sources}

Three similar European population-based primary care registries served as data sources: 1)the General Practice Research Database (GPRD) from the United Kingdom (UK, 19982008), 2)the Integrated Primary Care Information database (IPCI) from the Netherlands (1996-2007), and 3)the Health Search/CSD Longitudinal Patient Database (HSD) from Italy (2000-2007). In these three countries, all citizens are registered with a primary care practice, who acts as a gatekeeper to secondary and tertiary medical care. For each individual patient all relevant medical information from primary and secondary care, as well as additional information, including demographics and drug prescriptions, is recorded in the health care medical record. All three registries comply with European Union guidelines on the use of medical data for research. The protocol of the present study was approved by the Medical Ethics Committee of each database. We have previously shown the validity to combine and to compare data from these databases. ${ }^{17,19}$ For GPRD, the READ dictionary was used to identify medical diagnosis and symptoms, whereas the International Classification for Primary Care ${ }^{20}$ and the International Classification of Diseases, $9^{\text {th }}$ Revision, Clinical Modification (ICD-9-CM) ${ }^{2121}$ were used for that purpose in IPCI and HSD, respectively. In IPCI and HSD information on drug prescription was coded according to the Anatomical Therapeutical Chemical (ATC) classification. ${ }^{222}$ In GPRD information on drugs is captured with MULTILEX product dictionary and British National Formulary (BNF) codes.

\section{Determination of NSAID cohort}

The identification of the source population and NSAID cohort has been described elsewhere. ${ }^{17}$ In brief, a source population was identified within each database by inclusion of patients from start of the study period, 50 years of age or the date that one year of valid data within the database was available, whichever was the most recent. The one-year period prior to inclusion in the source population was required for valid assessment of baseline characteristics and inclusion and exclusion criteria at the time of NSAID prescription. A cohort of patients who newly started (i.e. no NSAID prescriptions within 6 months prior to inclusion) on either coxibs or nsNSAIDs (excluding the fixed combination of diclofenac with misoprostol) was identified. Exclusion criteria were history of gastrointestinal tract cancer, alcohol abuse, chronic liver disease, inflammatory bowel disease, or coagulopathy. Within the cohort of new users, all episodes of NSAID use were determined and defined as consecutive NSAID prescriptions with intervening gaps not exceeding the duration of the previous NSAID prescription(Figure 1). The duration of an NSAID episode was calculated by dividing the prescribed quantity by daily dose regimen (GPRD/IPCI) or the indicationspecific defined daily dose (HSD). The end of an NSAID episode was defined as the end of the duration of the last NSAID prescription within that episode or the end of follow-up, whichever was earliest. All episodes from a patient were eligible for inclusion if the 
previous NSAID-prescription ended at least 6 months before the start of the next episode. The density of NSAID use was calculated by the number of NSAID prescription days divided by episode length. Eligible gastroprotective agents (GPAs) were proton pump inhibitors (PPIs), double-dosed histamine 2 receptor antagonists $\left(\mathrm{H}_{2} \mathrm{RAs}\right)$, and misoprostol.

For the present study, non-selective NSAID users were excluded if they did not use a GPA concomitantly, or if they were non-adherent to the concomitantly used GPA (i.e. coverage of less than $80 \%$ of the nsNSAID days). In total, $68.1 \%$ of NSAID plus GPA users were highly adherent. ${ }^{17}$ The exposure assessment and GPA adherence calculation are schematically depicted in Figure 1. The GPA adherence calculation has been described previously. ${ }^{18}$ NSAID episodes during which patients switched between classes of NSAIDs (from nsNSAID to coxib or vice versa) were excluded. Episodes during which coxibs were used concurrently with a GPA were also excluded. Overall, in $83.4 \%$ of coxib episodes no GPA was used concomitantly. ${ }^{19}$ This resulted in a cohort including only nsNSAID plus GPA ( $\geq 80 \%$ adherence) and coxib (alone) users.

\section{Cases and controls selection}

Outcomes of interest were a composite of UGI events (including symptomatic ulceration, UGI bleeding (UGIB), perforation or obstruction) and UGIB alone. Identification of the outcomes has been described in more detail elsewhere. ${ }^{17}$ The date of outcome (i.e. index date) was determined as date of start of symptoms leading to the diagnosis of the UGI event, or if this date was unknown, date of diagnosis. Events occurring within 60 days after the end of an NSAID episode were attributed to the previous NSAID use. ${ }^{23}$

A nested case-control study was conducted. To each case experiencing an UGI event during or within 60 days after the end of an NSAID episode, we matched all control persons from the cohort of the corresponding database. Controls had not experienced any UGI event at the index date of the corresponding case and were at the index date alive, using an NSAID within 60 days prior, had equal number of UGI risk factors (see below) as the case and had similar age ( \pm 3 years) and same gender.

\section{Covariates}

We considered as risk factors for UGI events those that are commonly reported in literature: (i) age $\geq 65$ years; (ii) a history of UGI events (bleeding/ulceration); (iii) concurrent use of anticoagulants; (iv) concomitant use of antiplatelets (including aspirin $\leq 325 \mathrm{mg} /$ day); and (v) concomitant use of glucocorticoids (equipotent dose of $25 \mathrm{mg}$ prednisone). Presence of risk factors was determined by electronic searches in all available data prior to or noted at the index date.

Additional potential confounding factors were assessed: dyspepsia in the year before the NSAID episode, (history of) smoking, presence of heart failure or diabetes mellitus, and concomitant use of drugs associated with increased risk of bleeding (selective serotonin reuptake inhibitors (SSRI), spironolactone or calcium antagonists) at the index date.

\section{Statistical analyses}

Baseline characteristics of cases and controls were described by database and compared using univariate conditional logistic regression analyses.

To estimate the risk for UGI events and UGI bleeding among nsNSAID + GPA users( $\geq 80 \%$ adherence) in comparison to coxib users, matched and adjusted odds ratios (OR) with 95\% confidence intervals (CIs) were calculated using conditional logistic regression analyses for each database separately and as pooled analysis. The odds ratio can be interpreted as an 
estimate of the relative risk, as person-time is inherently accounted for in the analysis and the underlying source population is representative of the general population. ${ }^{24}$ The pooling of data across databases was performed by two methods: 1) on patient-level (respecting matched cases and controls from the original database); and 2) on study-level by estimating the risk of UGI events for nsNSAID + GPA( $\ 80 \%$ adherence) use versus coxib use per database and pooling the three obtained risk estimates using a meta-analytic approach, resulting in an overall risk estimate (inverse variance model) using a random-effects model. The latter method is only appropriate when there is no heterogeneity.

Identification of confounders was performed by entering each potential confounder into the model one by one and were kept in the final model if the risk estimate for the drug exposure changed by more than $10 \%$. As the duration coxibs use might differ from use of nsNSAIDs +GPA ( $\ 80 \%$ adherence) we adjusted also for duration of the episodes and density of NSAID use. Subsequent analyses evaluated the risk of UGI events and UGI bleeding stratified by the presence of individual risk factors: age $\ 65$ years, history of UGI event, and use of concomitant medications (antiplatelets, anticoagulants and glucocorticoids). For glucocorticoids, we considered an equipotent dose of prednisone 5 to $10 \mathrm{mg} /$ day as lowdosage; > 10 to $20 \mathrm{mg} /$ day as moderate dosage and >20 mg/day as high-dosage.

Multiplicative interaction was tested to identify effect modification by all of the individual UGI risk factors.

All analyses were performed using SPSS 15.0 for Windows (SPSS Inc, Chicago, Ill). Statistical significance was defined as a two-sided $\mathrm{p}$-value $<0.05$.

\section{Results}

\section{Patient characteristics}

We identified 384,469 new NSAID users in the United Kingdom (UK), 307 of who experienced an UGI event (194 with UGI bleeding). In the Netherlands 17 cases with an UGI event (14 with UGI bleeding) were identified from 55,004 new users of NSAIDs and in Italy 74 cases with an UGI event (17 with UGI bleeding) were identified from 177,747 new NSAID users. Overall, 57,568 event-free controls were matched to these 398 UGI event cases. Median number of controls was 120 per case (interquartile range: 43-201).

Baseline characteristics of the cases and matched controls are shown in Table 1. In the UK, the most commonly prescribed nsNSAID was ibuprofen (56\%), while celecoxib and rofecoxib were the most commonly prescribed coxibs ( $48 \%$ and $40 \%$, respectively). In NL, the most commonly prescribed coxib and nsNSAID were rofecoxib (58\%) and diclofenac (52\%), respectively. Diclofenac and nimesulide accounted for the greater part of nsNSAIDs in Italy (22\% and 25\%, respectively), whereas celecoxib (51\%) and rofecoxib (41\%) were the most frequently prescribed coxibs. Proton pump inhibitors comprised the majority of coprescribed GPAs in nsNSAID users across countries (UK:99.6\%, NL:97.0\%, IT:95.8\%).

In the UK, UGI event cases reported more often a history of UGI event (OR: 1.50; 95\% CI: 1.04-2.16) and used concomitant anticoagulant therapy (OR: 1.85; 95\% CI: 1.06-3.25) and SSRIs more frequently (OR: 1.92; 95\% CI: 1.33-2.77). In the Netherlands and Italy, UGI event cases were significantly more likely to receive concomitant antiplatelet therapy in comparison to controls $\left(\mathrm{OR}_{\mathrm{NL}}: 6.91 ; 95 \%\right.$ CI: $1.07-44.57$, and $\mathrm{OR}_{\mathrm{IT}}: 3.12 ; 95 \% \mathrm{CI}$ : 1.36-7.17). UGI bleeding cases in UK were more likely to receive concomitant anticoagulants (OR: 2.56; 95\% CI: 1.38-4.75), whereas no significant differences in anticoagulant use were observed between UGIB cases and controls in the Netherlands and Italy. From all UGI event cases in the UK, the Netherlands and Italy, respectively $11.7 \%$, 
$11.8 \%$ and $32.4 \%$ had no documented UGI risk factor. The majority of cases were identified as having one or two documented UGI risk factors.

Across all three countries, most NSAID episodes were of short duration (i.e. less than 1 month), ranging from $53 \%$ in the UK to $85 \%$ in IT. The proportion of patients treated for 1-6 months ranged from $14 \%$ in IT to $29 \%$ in UK, while $0.9 \%$ to $19 \%$ of patients in the three countries were treated for more than 6 months. The median duration of coxib episodes was 30 days (interquartile range: $20-91$ days) and median duration of nsNSAID +GPA ( $\ 80 \%$ adherence) episodes was 28 days (interquartile range: 14-79 days).

\section{Risk of UGI events and UGI bleeding}

To compare the risk of UGI event between use of coxibs alone versus highly adherent nsNSAID+GPA use, a nested case-control study was conducted. From the adjusted model, no statistically significant decreased or increased risk was observed for nsNSAID + GPA users ( $\triangle 80 \%$ adherence) as compared to coxib users (Table 2). This holds true for the three countries separately and as pooled estimates on patient level (Table 2). Regarding UGIB specifically, similar results were observed. For both outcomes, a trend towards a more protective effect for nsNSAID+GPA ( $280 \%$ adherence) as compared to coxibs was observed in the Netherlands and Italy (Table 2), but the adjusted model did not show a significant benefit (Table 2).

Meta-analysis of studies conducted at individual database-level using a random effects model (no significant heterogeneity between databases was shown, I-squared values of $0 \%$ ) did not report different results from pooling on patient-level. Using this meta-analytic approach, adjusted ORs for UGI events and UGI bleeding following nsNSAID+GPA ( $\geq 80 \%$ adherence) compared to coxib use were 1.00 (95\% CI: $0.73-1.33)$ and 1.11 (95\% CI: 0.76-1.63), respectively.

\section{Subgroup analyses}

Stratification according to the predefined individual UGI risk factors was performed to identify a possible preference for either strategy in specific risk groups (Table 3). Since most cases of UGI events occurred in subjects aged 75 years and older, we performed additional analyses taking a different cut-off age of 75 years, which did not demonstrate different estimates from the cut-off of 65 years (data not shown). In non-antiplatelet users a nonsignificant increased risk both for UGI events and UGI bleeding was observed for nsNSAID +GPA ( $\geq 80 \%$ adherence), whereas the opposite was found for antiplatelet users. This interaction term was significant.

When we compared coxib use with highly adherent nsNSAID+GPA use in glucocorticoid users, the use of nsNSAID+GPA increased the risk for UGI events considerably (OR: 7.03; 95\% CI 1.35-36.45)(P=0.020). When adjusting for the dosage of glucocorticoids, the estimated risk increased even more (OR: 9.01; 95\% CI: 1.61-50.50)( $\mathrm{P}=0.012)$. Higher dosage of glucocorticoids affected the risk of UGI events more as a dose-response relationship was observed (data not shown). Regarding multiplicative interaction, the interaction term for use of glucocorticoids was not significant.

The withdrawal of rofecoxib from the market in 2004 influenced in general the prescription pattern of NSAIDs. After 2004 only celecoxib, etoricoxib, valdecoxib and parecoxib were available in Europe. Therefore, stratification according to time period was performed. A decrease in percentage of cases and controls using a coxib was noticed after rofecoxib was not available on the market anymore. However, this did not impact on the risk of an UGI event for nsNSAIDs+GPA versus coxibs (Table 3). 


\section{Discussion}

In this case-control study we demonstrate that the risk of an UGI event or UGI bleeding is not different between users of non-selective (ns)NSAIDs in combination with adherent use of a gastroprotective agent (GPA) and coxib users.

Lowering the risk of NSAID-related UGI events can be achieved by concomitant use of GPAs. In particular increasing adherence to GPAs is important in reducing the risk nsNSAID-related UGI events. ${ }^{16-18}$ As another preventive strategy, COX-2- selective inhibitors were developed to improve the gastrointestinal safety of NSAID therapy, especially in high-risk patients such as elderly (aged $\ 65$ years) patients, those with a history of UGI events or concomitantly using anticoagulants, antiplatelets or corticosteroids. After the introduction of coxibs, it was shown that they indeed were associated with less gastrointestinal toxicity as compared to the traditional non-selective NSAIDs alone. 11, 25-27 Several studies on this topic have been published in recent years. ${ }^{28}$ Though the implementation of preventive strategies has increased in recent years, there is still room for considerable improvement with regard to use of preventive strategies during NSAID therapy. ${ }^{16,29}$ In order to investigate which preventive strategy is superior with regard to UGI safety, head-to-head comparisons between coxibs and NSAIDs combined with GPAs have been performed in randomized studies. These studies showed no preference of one strategy over the other. ${ }^{5-7,9-10}$ However, most clinical studies do not allow generalization of their results to daily clinical practice in Western countries, since many studies included selected categories of patients (i.e. high-risk patients with endoscopically documented UGI bleed/ulcer- or with specific disease, in particular rheumatoid arthritis), were performed in non-Caucasian persons, and in persons at very high risk of an UGI event.

Our results are in keeping with another observational study by Targownik et al. showing no superiority of nsNSAID combined with PPI use to coxibs in the prevention of NSAIDrelated UGI events. ${ }^{14}$ Although the efficacy of both preventive strategies overall seems equivalent for the upper gastrointestinal tract in the CONDOR study, the coxib-treated patients appeared to have a reduced risk of lower GI events as compared to nsNSAID plus PPI use. ${ }^{10,30}$ However, results from other studies evaluating lower GI tract events as an outcome were conflicting. ${ }^{31-34}$ A post hoc analysis of a prospective study showed a lower rate of serious lower GI events for rofecoxib compared to naproxen ${ }^{30}$, whereas this was not confirmed in a cross-sectional capsule enteroscopy study showing comparable small-bowel damage between long-term NSAID and coxib users. ${ }^{34}$ Mechanistically, whether the impact of NSAIDs on lower GI events reflect a reduction in risk by coxib-use or an increase in risk by PPI-use due to altered intestinal bacteria and increased susceptibility to small intestinal bacterial overgrowth is still under debate. ${ }^{35}$ Another area of potential benefit of coxibs over nsNSAID plus GPA use might be in selected high-risk groups. In this study, we found that in glucocorticoid users, adherent use of an nsNSAID plus GPA was associated with a nine times higher UGI event risk compared to coxibs. This finding is supported by the doseresponse relationship we observed where a higher dosage of glucocorticoids affected the risk of UGI events more than a lower dosage. The interaction term was not significant, but this is due to limited power since the estimates differed largely. To our knowledge, no previous study studied the comparison of coxib and nsNSAID plus GPA use in glucocorticoid users separately. Although data on glucocorticoids as an independent risk factor for UGI events are scarce, prior studies have shown a two-fold increased risk of UGI bleeding during glucocorticoid use alone. ${ }^{36-39}$ When glucocorticoids are used in combination with NSAIDs, the risk of UGI bleeding is estimated higher as compared to NSAID use alone or glucocorticoid use alone. ${ }^{36-39} \mathrm{Up}$ to now, the reason for the interaction between both drugs has not been elucidated. One might speculate that glucocorticoids and NSAIDs act synergistically; experimental studies have shown that glucocorticoids inhibit the healing of 
gastric mucosal damage ${ }^{40-41}$ as well as NSAIDs do, although the mechanism of inhibition differs. Alternatively, gastric bacterial overgrowth due to acid-suppression such as occurs by PPI use ${ }^{42-43}$ might aggravate gastric mucosal damage by increased exposure time of gastric flora to the mucosal surface or by delayed gastric emptying caused by PPIs. ${ }^{44}$ The combination of nsNSAIDs and PPIs therefore may have led to the observed increased risk in concurrent glucocorticoid users. As use of steroids is a risk factor that according to guidelines often will initiate GPA in NSAID-treated patients, this aspect is important to investigate in future studies.

Although not significant, we found a tendency towards an increased UGI event risk in patients with a history of an UGI event among nsNSAID plus adherent GPA users as compared to coxib users. In this particular high-risk patient group, one might consider the addition of a GPA to a coxib. This combination has been shown to reduce the risk of NSAID-related UGI events to a higher degree than coxibs alone or nsNSAIDs plus PPIs. ${ }^{14}$

In line with previous studies, concomitant use of low-dose aspirin seems to eliminate the UGI risk benefit of coxibs. ${ }^{12,26-27,45}$ Though not significant, we observed an increased UGI risk among nsNSAID plus adherent GPA compared to coxib users who did not concomitantly use aspirin, whereas the opposite was true for concomitant aspirin users. The interaction term was significant, pointing to an increase in risk of UGI events for coxibs when aspirin is used concurrently. In patients concomitantly using antiplatelets (including low-dose aspirin), GPAs should be recommended not only to nsNSAIDs users, but perhaps also to coxib users. ${ }^{3,14,19}$ The strength of the current study is the scale and setting: primary health care data from three European countries were combined reflecting real-life prescription patterns. Due to the setting it was possible to study both low-risk as well as high-risk patients. Previous evidence from clinical trials focused generally on high risk patients only. ${ }^{5-7}$

The following limitations should be acknowledged. By performing observational studies, certain biases can be introduced of which confounding-by-indication is the most important one to discuss. Confounding-by-indication could have been introduced as the general practitioner's awareness of the UGI risk profile of the individual patient might have influenced the prescribed preventive strategy. After the introduction of coxibs, high-risk patients were more likely to receive a coxib instead of co-prescription of a GPA to NSAIDs. ${ }^{46}$ Nevertheless, the preference for preventive strategies changed after warnings for an increased cardiovascular risk related to coxibs were released by regulatory agencies. ${ }^{47}$ Although the risk of UGI complications with rofecoxib used to be higher than with celecoxib ${ }^{48}$, in a stratified analysis the estimate of nsNSAIDs plus GPAs compared to coxibs without rofecoxib after 2004 (i.e. celecoxib, etoricoxib, valdecoxib and lumiracoxib only) did not differ from the estimate including rofecoxib (before withdrawal). It is therefore unlikely that data on the use of rofecoxib prior to its withdrawal would have skewed the GI safety data in favor of the nsNSAID. We feel that it is therefore unlikely that the channeling away from coxibs for patients with cardiovascular disease would have led to important confounding.

We tried to address confounding-by-indication by matching on the number of UGI risk factors and by restricting the comparator group to nsNSAID users who were highly adherent to GPA (defined as at least $80 \%$ of nsNSAID days covered by a GPA prescription). Although crude incidence rates appeared to be equal between different levels of GPA adherence ${ }^{17}$, from previous studies we know that patients being adherent to the prescribed GPA are at the highest risk of nsNSAID related UGI events. ${ }^{17-18}$ Residual confounding due to exclusion of users with a lower GPA adherence level is therefore unlikely. In addition, we selected patient groups with a similar UGI risk profile, by matching on number of UGI risk 
factors, as well as gender and age. Comparison between coxib and nsNSAID plus highly adherent GPA users showed no differences in number of UGI risk factors. Confounding was also dealt with by adjusting for several co-morbid conditions. The indication of glucocorticoid use could only be identified in the Netherlands, of which $64 \%$ was for rheumatoid disorders. Nevertheless, residual confounding cannot be ruled out in observational studies.

In addition, over-the-counter use of nsNSAIDs and GPA is not recorded in the databases and could have led to a potential underestimation of its use. We used drug prescription data rather than precise information on the actual use. Furthermore, the method of GPA adherence calculation used in the present study determined adherence based on days of GPA and of nsNSAID use, rather than daily coverage. However, we selected a group of highly adherent nsNSAID plus GPA users based on a cut off of $80 \%$ of GPA adherence.

In conclusion, there is no difference in the risk of UGI events between the use of coxibs and use of nsNSAIDs plus adherent GPA in daily clinical practice. Neither strategy was superior in the prevention of a first or a recurrent UGI event or UGI bleeding. A significant increase in the risk of UGI events for coxibs was observed when aspirin is used concurrently, whereas during concomitant glucocorticoid use nsNSAID plus GPA users are at increased risk of an UGI event compared to coxib users. Future studies on this topic are needed, as use of steroids is a risk factor that, according to guidelines, often will initiate GPA therapy in NSAID-treated patients.

\section{Supplementary Material}

Refer to Web version on PubMed Central for supplementary material.

\section{Footnotes}

Correspondence to: Gwen MC Masclee, M.D. Dept. of Medical Informatics Erasmus University Medical Center PO Box 20403000 CA Rotterdam The Netherlands Phone: +31 107044116 Fax: +31 107044722 g.masclee@erasmusmc.nl

Guarantor of the article: Gwen MC Masclee

Author Contributions: Gwen MC Masclee: acquisition of data; analysis and interpretation of data; drafting of the manuscript; statistical analysis

Vera E Valkhoff: study concept and design; acquisition of data; analysis and interpretation of data; drafting of the manuscript; statistical analysis.

Eva M van Soest: study concept and design; acquisition of data; drafting of the manuscript; critical revision of the manuscript for important intellectual content; study supervision.

Giampiero Mazzaglia: acquisition of data; critical revision of the manuscript for important intellectual content Mariam Molokhia: acquisition of data; critical revision of the manuscript for important intellectual content René Schade: acquisition of data; critical revision of the manuscript for important intellectual content Gianluca Trifirò: acquisition of data; critical revision of the manuscript for important intellectual content Jay L Goldstein: acquisition of data; critical revision of the manuscript for important intellectual content Sonia Hernández-Dí az: acquisition of data; critical revision of the manuscript for important intellectual content Ernst J Kuipers: analysis and interpretation of data; critical revision of the manuscript for important intellectual content

Miriam C J M Sturkenboom: study concept and design; acquisition of data; analysis and interpretation of data; critical revision of the manuscript for important intellectual content; obtained funding; study supervision All authors approved the final version of the manuscript.

Financial support:

Authors' declaration of personal interests:

- GMCM, VV, ES, GM, RS and GT do not have any conflict of interest. 
- MM has received grants from the SAEC consortium (collaboration of academia and industry), and from AstraZeneca, Pfizer. MM's work on drug safety is supported by the National Institute for Health Research (NIHR) Biomedical Research Centre at Guy's and St Thomas' NHS Foundation Trust and King's College London.

- JG has received research and/or educational funding, consulting fees, contract payments and speaker's honoraria from AstraZeneca, Horizon, Logical Therapeutics, Pfizer and POZEN. He has received consulting fees from Boehringer Ingelheim.

- SHD has consulted for AstraZeneca, Novartis, and GSK. The Pharmaco-epidemiology Program at the Harvard School of Public Health has been partially supported by training grants from Pfizer, Novartis and Asia.

- EJK has served as speaker and advisory board member for AstraZeneca.

- MS is head of an academic unit that conducts some research for pharmaceutical companies: Pfizer, Lilly, AstraZeneca, Boehringer Ingelheim. All research is done under the condition of publication freedom.

\section{Acknowledgments}

Declaration of funding interests: This study has been funded by AstraZeneca PLC under contractual conditions with Erasmus University that ensure freedom of publication. The study was designed and conducted independently from AstraZeneca.

\section{Abbreviations}

$\begin{array}{ll}\text { ATC } & \text { Anatomical Therapeutic Chemical } \\ \text { BNF } & \text { British National Formulary } \\ \text { CI } & \text { Confidence Interval } \\ \text { COX } & \text { Cyclo-oxygenase } \\ \text { Coxib } & \text { Cyclooxygenase-2 inhibitor } \\ \text { GPA } & \text { Gastroprotective Agent } \\ \text { GPRD } & \text { General Practitioner Research Database } \\ \text { H2RA } & \text { Histamine-2-receptor Antagonist } \\ \text { HSD } & \text { Health Search/CSD Longitudinal Patient Database } \\ \text { ICD-9-CM } & \text { International Classification of Diseases, } 9^{\text {th }} \text { Revision, Clinical Modification } \\ \text { IPCI } & \text { Integrated Primary Care Information database } \\ \text { NA } & \text { Not applicable } \\ \text { N adh } & \text { Non adherent } \\ \text { NSAID } & \text { Non-Steroidal Anti-inflammatory Drug } \\ \text { NSNSAID } & \text { Non-selective Non-Steroidal Anti-inflammatory Drug } \\ \text { OR } & \text { Odds Ratio } \\ \text { OTC } & \text { Over-the-counter } \\ \text { PPI } & \text { Proton Pump Inhibitor } \\ \text { UGI } & \text { Upper Gastro-Intestinal } \\ \text { UK } & \text { United Kingdom }\end{array}$




\section{References}

1. Recommendations for the medical management of osteoarthritis of the hip and knee: 2000 update. American College of Rheumatology Subcommittee on Osteoarthritis Guidelines. Arthritis Rheum. 2000; 43(9):1905-15. [PubMed: 11014340]

2. Scottish Intercollegiate Guidelines Network. Control of pain in adults with cancer (Guideline 106). SIGN; Edinburgh: 2008.

3. Lanza FL, Chan FK, Quigley EM. Guidelines for prevention of NSAID-related ulcer complications. Am J Gastroenterol. 2009; 104(3):728-38. [PubMed: 19240698]

4. Moens HJ, van Croonenborg JJ, Al MJ, van den Bemt PM, Lourens J, Numans ME. [Guideline 'NSAID use and the prevention of gastric damage']. Ned Tijdschr Geneeskd. 2004; 148(13):604-8. [PubMed: 15083624]

5. Lai KC, Chu KM, Hui WM, et al. Celecoxib compared with lansoprazole and naproxen to prevent gastrointestinal ulcer complications. Am J Med. 2005; 118(11):1271-8. [PubMed: 16271912]

6. Chan FK, Hung LC, Suen BY, et al. Celecoxib versus diclofenac plus omeprazole in high-risk arthritis patients: results of a randomized double-blind trial. Gastroenterology. 2004; 127(4):103843. [PubMed: 15480981]

7. Chan FK, Hung LC, Suen BY, et al. Celecoxib versus diclofenac and omeprazole in reducing the risk of recurrent ulcer bleeding in patients with arthritis. N Engl J Med. 2002; 347(26):2104-10. [PubMed: 12501222]

8. Simon LS, Weaver AL, Graham DY, et al. Anti-inflammatory and upper gastrointestinal effects of celecoxib in rheumatoid arthritis: a randomized controlled trial. JAMA. 1999; 282(20):1921-8. [PubMed: 10580457]

9. Goldstein JLCB, Amer F, Hunt B. Celecoxib plus aspirin versus naproxen and lansoprazole plus aspirin: a randomized, double-blind, endoscopic trial. Clin Gastroenterol Hepatol. 2007; 5(10): 1167-1174. [PubMed: 17916545]

10. Chan FK, Lanas A, Scheiman J, Berger MF, Nguyen H, Goldstein JL. Celecoxib versus omeprazole and diclofenac in patients with osteoarthritis and rheumatoid arthritis (CONDOR): a randomised trial. Lancet. 2010; 376(9736):173-9. [PubMed: 20638563]

11. Schnitzer TJ, Burmester GR, Mysler E, et al. Comparison of lumiracoxib with naproxen and ibuprofen in the Therapeutic Arthritis Research and Gastrointestinal Event Trial (TARGET), reduction in ulcer complications: randomised controlled trial. Lancet. 2004; 364(9435):665-74. [PubMed: 15325831]

12. Lanas A, Garcia-Rodriguez LA, Arroyo MT, et al. Risk of upper gastrointestinal ulcer bleeding associated with selective cyclo-oxygenase- 2 inhibitors, traditional non-aspirin non-steroidal antiinflammatory drugs, aspirin and combinations. Gut. 2006; 55(12):1731-8. [PubMed: 16687434]

13. Rahme E, Barkun AN, Toubouti Y, Scalera A, Rochon S, Lelorier J. Do proton-pump inhibitors confer additional gastrointestinal protection in patients given celecoxib? Arthritis Rheum. 2007; 57(5):748-55. [PubMed: 17530673]

14. Targownik LE, Metge CJ, Leung S, Chateau DG. The relative efficacies of gastroprotective strategies in chronic users of nonsteroidal anti-inflammatory drugs. Gastroenterology. 2008; 134(4):937-44. [PubMed: 18294634]

15. Van der Linden MW, Gaugris S, Kuipers EJ, Van den Bemt BJ, van Herk-Sukel MP, Herings RM. Gastroprotection among new chronic users of non-steroidal anti-inflammatory drugs: a study of utilization and adherence in The Netherlands. Curr Med Res Opin. 2009; 25(1):195-204. [PubMed: 19210152]

16. van Soest EM, Sturkenboom MC, Dieleman JP, Verhamme KM, Siersema PD, Kuipers EJ. Adherence to gastroprotection and the risk of NSAID-related upper gastrointestinal ulcers and haemorrhage. Aliment Pharmacol Ther. 2007; 26(2):265-75. [PubMed: 17593072]

17. van Soest EM, Valkhoff VE, Mazzaglia G, et al. Suboptimal gastroprotective coverage of NSAID use and the risk of upper gastrointestinal bleeding and ulcers: an observational study using three European databases. Gut. 2011; 60(12):1650-1659. [PubMed: 21636644] 
18. Goldstein JL, Howard KB, Walton SM, McLaughlin TP, Kruzikas DT. Impact of adherence to concomitant gastroprotective therapy on nonsteroidal-related gastroduodenal ulcer complications. Clin Gastroenterol Hepatol. 2006; 4(11):1337-45. [PubMed: 17088110]

19. Valkhoff VE, van Soest EM, Mazzaglia G, et al. Adherence to gastroprotection during cyclooxygenase- 2 inhibitor use and the risk of upper gastrointestinal events: A population-based study. Arthritis Rheum. 2012; 64(8):2792-2802. [PubMed: 22508379]

20. Lamberts H, Wood M, Hofmans-Okkes IM. International primary care classifications: the effect of fifteen years of evolution. Fam Pract. 1992; 9(3):330-9. [PubMed: 1459391]

21. World Health Organization. [accessed March 19, 2013] Classification of Diseases. Available at: http://www.who.int/classifications/icd/en/

22. WHO Collaborating Centre for Drug Statistics Methodology. [accessed March 19, 2013] Guidelines for ATC classification and DDD assignment. http://www.whocc.no/atcddd/

23. Hernandez-Diaz S, Rodriguez LA. Association between nonsteroidal anti-inflammatory drugs and upper gastrointestinal tract bleeding/perforation: an overview of epidemiologic studies published in the 1990s. Arch Intern Med. 2000; 160(14):2093-9. [PubMed: 10904451]

24. MacMahon, B.; Trichopoulos, D. Epidemiology: Principles and Methods. 2nd ed. 1996. Casecontrol studies.

25. Bombardier C, Laine L, Reicin A, et al. Comparison of upper gastrointestinal toxicity of rofecoxib and naproxen in patients with rheumatoid arthritis. VIGOR Study Group. N Engl J Med. 2000; 343(21):1520-8. 2 p following 1528.

26. Silverstein FE, Faich G, Goldstein JL, et al. Gastrointestinal toxicity with celecoxib vs nonsteroidal anti-inflammatory drugs for osteoarthritis and rheumatoid arthritis: the CLASS study: A randomized controlled trial. Celecoxib Long-term Arthritis Safety Study. JAMA. 2000; 284(10): 1247-55.

27. Goldstein JL, Correa P, Zhao WW, et al. Reduced incidence of gastroduodenal ulcers with celecoxib, a novel cyclooxygenase-2 inhibitor, compared to naproxen in patients with arthritis. Am J Gastroenterol. 2001; 96(4):1019-27. [PubMed: 11316141]

28. Micklewright R, Lane S, Linley W, McQuade C, Thompson F, Maskrey N. Review article: NSAIDs, gastroprotection and cyclo-oxygenase-II-selective inhibitors. Aliment Pharmacol Ther. 2003; 17(3):321-32. [PubMed: 12562444]

29. Valkhoff VE, van Soest EM, Sturkenboom MC, Kuipers EJ. Time-trends in gastroprotection with nonsteroidal anti-inflammatory drugs (NSAIDs). Aliment Pharmacol Ther. 2010; 31(11):1218-28. [PubMed: 20222917]

30. Laine L, Connors LG, Reicin A, et al. Serious lower gastrointestinal clinical events with nonselective NSAID or coxib use. Gastroenterology. 2003; 124(2):288-92. [PubMed: 12557133]

31. Laine L, Curtis SP, Langman M, et al. Lower gastrointestinal events in a double-blind trial of the cyclo-oxygenase- 2 selective inhibitor etoricoxib and the traditional nonsteroidal anti-inflammatory drug diclofenac. Gastroenterology. 2008; 135(5):1517-25. [PubMed: 18823986]

32. Goldstein JL, Eisen GM, Lewis B, et al. Small bowel mucosal injury is reduced in healthy subjects treated with celecoxib compared with ibuprofen plus omeprazole, as assessed by video capsule endoscopy. Aliment Pharmacol Ther. 2007; 25(10):1211-22. [PubMed: 17451567]

33. Hawkey CJ, Ell C, Simon B, et al. Less small-bowel injury with lumiracoxib compared with naproxen plus omeprazole. Clin Gastroenterol Hepatol. 2008; 6(5):536-44. [PubMed: 18242145]

34. Maiden L, Thjodleifsson B, Seigal A, et al. Long-term effects of nonsteroidal anti-inflammatory drugs and cyclooxygenase- 2 selective agents on the small bowel: a cross-sectional capsule enteroscopy study. Clin Gastroenterol Hepatol. 2007; 5(9):1040-5. [PubMed: 17625980]

35. Wallace JL, Syer S, Denou E, et al. Proton pump inhibitors exacerbate NSAID-induced small intestinal injury by inducing dysbiosis. Gastroenterology. 2011; 141(4):1314-22. 1322, e1-5. [PubMed: 21745447]

36. Garcia Rodriguez LA, Lin KJ, Hernandez-Diaz S, Johansson S. Risk of upper gastrointestinal bleeding with low-dose acetylsalicylic acid alone and in combination with clopidogrel and other medications. Circulation. 2011; 123(10):1108-15. [PubMed: 21357821] 
37. Gutthann SP, Garcia Rodriguez LA, Raiford DS. Individual nonsteroidal antiinflammatory drugs and other risk factors for upper gastrointestinal bleeding and perforation. Epidemiology. 1997; 8(1):18-24. [PubMed: 9116088]

38. Hernandez-Diaz S, Rodriguez LA. Steroids and risk of upper gastrointestinal complications. Am J Epidemiol. 2001; 153(11):1089-93. [PubMed: 11390328]

39. Piper JM, Ray WA, Daugherty JR, Griffin MR. Corticosteroid use and peptic ulcer disease: role of nonsteroidal anti-inflammatory drugs. Ann Intern Med. 1991; 114(9):735-40. [PubMed: 2012355]

40. Luo JC, Shin VY, Liu ES, et al. Dexamethasone delays ulcer healing by inhibition of angiogenesis in rat stomachs. Eur J Pharmacol. 2004; 485(1-3):275-81. [PubMed: 14757151]

41. Luo JC, Cho CH, Ng KM, et al. Dexamethasone inhibits tumor necrosis factor-alpha-stimulated gastric epithelial cell migration. J Chin Med Assoc. 2009; 72(10):509-14. [PubMed: 19837644]

42. Fried M, Siegrist H, Frei R, et al. Duodenal bacterial overgrowth during treatment in outpatients with omeprazole. Gut. 1994; 35(1):23-6. [PubMed: 8307444]

43. Thorens J, Froehlich F, Schwizer W, et al. Bacterial overgrowth during treatment with omeprazole compared with cimetidine: a prospective randomised double blind study. Gut. 1996; 39(1):54-9. [PubMed: 8881809]

44. Parkman HP, Urbain JL, Knight LC, et al. Effect of gastric acid suppressants on human gastric motility. Gut. 1998; 42(2):243-50. [PubMed: 9536950]

45. Laine L, Maller ES, Yu C, Quan H, Simon T. Ulcer formation with low-dose enteric-coated aspirin and the effect of COX-2 selective inhibition: a double-blind trial. Gastroenterology. 2004; 127(2): 395-402. [PubMed: 15300570]

46. Alacqua M, Trifiro G, Cavagna L, et al. Prescribing pattern of drugs in the treatment of osteoarthritis in Italian general practice: the effect of rofecoxib withdrawal. Arthritis Rheum. 2008; 59(4):568-74. [PubMed: 18383398]

47. FDA US Food and Drug Administration Publich Health Advisory.

48. Rostom A, Muir K, Dube C, Lanas A, Jolicoeur E, Tugwell P. Prevention of NSAID-related upper gastrointestinal toxicity: a meta-analysis of traditional NSAIDs with gastroprotection and COX-2 inhibitors. Drug Healthc Patient Saf. 2009; 1:47-71. [PubMed: 21701610] 


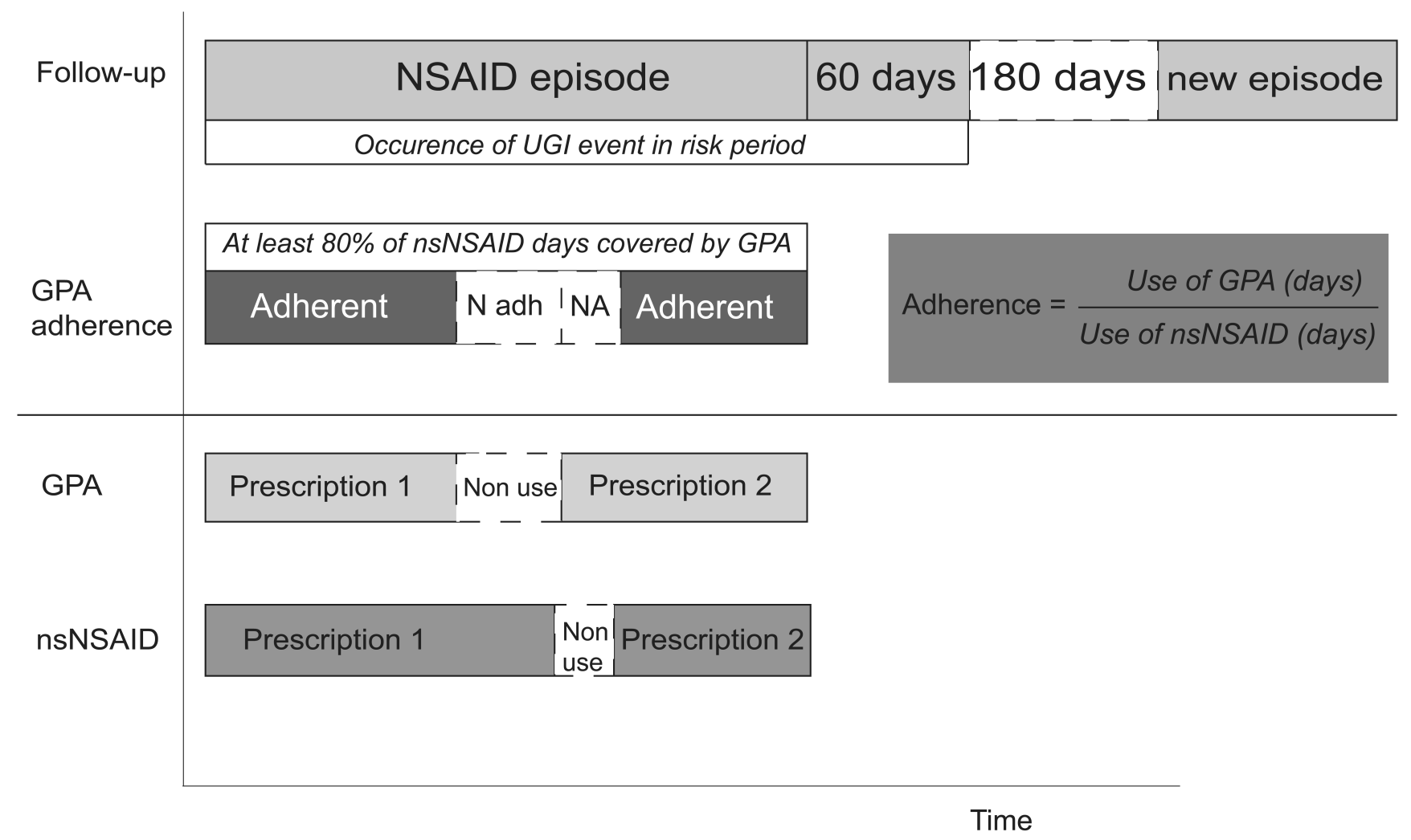

Figure 1. 
Table 1

Baseline characteristics of cases with symptomatic UGI events (UGI bleeding and symptomatic ulcer) and matched controls by database.

\begin{tabular}{|c|c|c|c|c|c|c|c|c|c|}
\hline & \multicolumn{2}{|c|}{ United Kingdom } & \multirow[b]{2}{*}{$\begin{array}{c}\text { P- } \\
\text { value }\end{array}$} & \multicolumn{2}{|c|}{ The Netherlands } & \multirow[b]{2}{*}{$\begin{array}{c}\text { P- } \\
\text { value }\end{array}$} & \multicolumn{2}{|c|}{ Italy } & \multirow[b]{2}{*}{ P-value } \\
\hline & $\begin{array}{c}\text { cases } \\
\mathrm{N}=307\end{array}$ & $\begin{array}{c}\text { controls } \\
\mathrm{N}=48,860\end{array}$ & & $\begin{array}{l}\text { cases } \\
\mathrm{N}=17\end{array}$ & $\begin{array}{c}\text { controls } \\
\mathrm{N}=374\end{array}$ & & $\begin{array}{l}\text { cases } \\
\mathrm{N}=74\end{array}$ & $\begin{array}{l}\text { controls } \\
\mathrm{N}=\mathbf{8 , 3 3 4}\end{array}$ & \\
\hline & $\mathbf{n}(\%)$ & $\mathbf{n}(\%)$ & & $\mathbf{n}(\%)$ & $\mathbf{n}(\%)$ & & $\mathbf{n}(\%)$ & $\mathbf{n}(\%)$ & \\
\hline Age in yrs (mean \pm sd) $*$ & $74.0(10.9)$ & $71.2(9.5)$ & NA & $75.0(9.6)$ & $73.9(9.7)$ & NA & $69.9(10.4)$ & $68.5(9.4)$ & NA \\
\hline Age category: $*$ & & & $\mathrm{NA}$ & & & NA & & & NA \\
\hline $50-64$ & $60(19.5)$ & $12,222(25.0)$ & & $2(11.8)$ & $63(16.8)$ & & $26(35,1)$ & 3,385 (40.6) & \\
\hline $65-74$ & $101(32.9)$ & $18,422(37.7)$ & & $6(35.3)$ & $119(31.8)$ & & $22(29,7)$ & $2,534(30.4)$ & \\
\hline$\geq 75$ & $146(47.6)$ & $18,216(37.3)$ & & $9(52.9)$ & $192(51.3)$ & & $26(35,1)$ & $2,415(29.0)$ & \\
\hline Gender $(\mathbf{n}(\%)$ male $) *$ & $132(43.0)$ & $13,544(27.7)$ & $\mathrm{NA}$ & $5(29.4)$ & $71(19.0)$ & NA & $20(27.0)$ & $1,668(20.0)$ & NA \\
\hline \multicolumn{10}{|l|}{ UGI risk factors: } \\
\hline Age $\geq 65$ yrs & $247(80.5)$ & $36,638(75.0)$ & 0.243 & $15(88.2)$ & $311(83.2)$ & - & $48(64.9)$ & $4,949(59.4)$ & 0.670 \\
\hline Prior UGI event & 57 (18.6) & $2,634(5.4)$ & 0.028 & $1(5.9)$ & $4(1.1)$ & 0.694 & $2(2.7)$ & $101(1.2)$ & 0.282 \\
\hline Use of antiplatelets & $106(34.5)$ & $11,647(23.8)$ & 0.123 & $10(58.8)$ & $86(23.0)$ & 0.042 & $12(16.2)$ & $329(3.9)$ & 0.007 \\
\hline Use of anticoagulants & $14(4.6)$ & $676(1.4)$ & 0.032 & $1(5.9)$ & $14(3.7)$ & 0.912 & $0(0)$ & $36(0.4)$ & - \\
\hline Use of glucocorticoids & $18(5.9)$ & $1,298(2.7)$ & 0.289 & $0(0)$ & $11(2.9)$ & - & $3(4.1)$ & $98(1.2)$ & 0.143 \\
\hline Number of UGI risk factors: $*$ & & & $\mathrm{NA}$ & & & NA & & & NA \\
\hline 0 & $36(11.7)$ & $10,578(21.6)$ & & $2(11.8)$ & $61(16.3)$ & & $24(32.4)$ & $3,300(39.6)$ & \\
\hline 1 & $131(42.7)$ & $24,332(49.8)$ & & $4(23.5)$ & $205(54.8)$ & & $35(47.3)$ & $4,567(54.8)$ & \\
\hline 2 & $112(36.5)$ & $13,310(27.2)$ & & $10(58.8)$ & $103(27.5)$ & & $15(20.3)$ & $455(5.5)$ & \\
\hline 3 & $25(8.1)$ & $619(1.3)$ & & $1(5.9)$ & $5(1.3)$ & & $0(0)$ & $12(0.1)$ & \\
\hline 4 & $3(1)$ & $21(0)$ & & & & & & & \\
\hline \multicolumn{10}{|l|}{ Other comorbidities: } \\
\hline Dyspepsia & $14(4.6)$ & $1,613(3.3)$ & 0.222 & $1(5.9)$ & $16(4.3)$ & 0.555 & $2(2.7)$ & $296(3.6)$ & 0.770 \\
\hline Smoking & $252(82.1)$ & $39,153(80.1)$ & 0.272 & $4(23.5)$ & $54(14.4)$ & 0.599 & $3(4.1)$ & $278(3.3)$ & 0.714 \\
\hline Heart Failure & $31(10.1)$ & $2,101(4.3)$ & 0.158 & $0(0)$ & $34(9.1)$ & - & $1(1.4)$ & $138(1.7)$ & 0.487 \\
\hline Diabetes mellitus & $63(20.5)$ & $6,542(13.4)$ & 0.062 & $2(11.8)$ & $62(16.6)$ & 0.525 & $13(17.6)$ & $878(10.5)$ & 0.151 \\
\hline \multicolumn{10}{|c|}{ Concomitant use of other medication: } \\
\hline SSRIs & $34(11.1)$ & $3,071(6.3)$ & $<0.001$ & $0(0)$ & $14(3.7)$ & - & $1(1.4)$ & $29(0.3)$ & 0.341 \\
\hline Spironolactone & $5(1.6)$ & $391(0.8)$ & 0.423 & $0(0)$ & $6(1.6)$ & - & (0) & (0) & - \\
\hline calcium channel blockers & $68(22.1)$ & $7,619(15.6)$ & 0.097 & $0(0)$ & $45(12.0)$ & - & (0) & (0) & 0.646 \\
\hline \multicolumn{10}{|l|}{ Duration of episode ${ }^{\# \text { : }}$} \\
\hline$<1$ month & $151(49.2)$ & $25,888(53.0)$ & 0.150 & $6(35.3)$ & $254(67.9)$ & 0.046 & $66(89.2)$ & $7,111(85.3)$ & 0.329 \\
\hline 1-6 months & $106(34.5)$ & $13,921(28.5)$ & 0.036 & $8(47.1)$ & $95(25.4)$ & 0.025 & $7(9.5)$ & $1,151(13.8)$ & 0.440 \\
\hline 6-12 months & $24(7.8)$ & $4,095(8.4)$ & 0.859 & $1(5.9)$ & $14(3.7)$ & 0.306 & $0(0)$ & $48(0.6)$ & - \\
\hline$<12$ months & $26(8.5)$ & $4,956(10.1)$ & 0.842 & $2(11.8)$ & $11(2.9)$ & 0.025 & $1(1.4)$ & $24(0.3)$ & 0.098 \\
\hline
\end{tabular}

Matching variables: age, gender and number of individual UGI risk factors.

SSRIs, selective serotonin reuptake inhibitors.

NA, Not applicable; matching criteria.

\# Episodes of NSAID use were defined as consecutive NSAID prescriptions with intervening gaps not exceeding the duration of the previous NSAID prescription. The duration of an NSAID episode was calculated by dividing the prescribed quantity by daily dose regimen (United Kingdom/Netherlands) or the indication-specific defined daily dose (Italy). The end of an NSAID episode was defined as the end of the duration of the last NSAID prescription within that episode or the end of follow-up, whichever was earliest. 
Table 2

The risk of symptomatic UGI events and UGI bleeding in users of nsNSAID+GPA ( $\$ 0 \%$ adherence) as compared to coxib users.

\begin{tabular}{|c|c|c|c|c|c|c|c|c|c|c|c|c|c|}
\hline & & \multicolumn{6}{|c|}{ Symptomatic UGI events (UGI bleeding and symptomatic ulcer) } & \multicolumn{6}{|c|}{ UGI bleeding } \\
\hline & & Cases & Controls & $\begin{array}{c}\text { ORmatch } \\
\text { ed } \\
(95 \% \mathrm{CI})\end{array}$ & $\begin{array}{c}\text { P- } \\
\text { value }\end{array}$ & $\underset{(\mathbf{9 5 \%} \% \mathrm{CI})}{\mathrm{ORadj}^{\dagger}}$ & $\begin{array}{c}\mathbf{P -} \\
\text { value }\end{array}$ & Cases & Controls & $\begin{array}{l}\text { ORmatche } \\
\text { d }(95 \% \text { CI })\end{array}$ & P-value & $\underset{(95 \% \mathrm{CI})}{\text { ORadj }}{ }^{\dagger}$ & P-value \\
\hline & & $\mathrm{n}(\%)$ & $\mathrm{n}(\%)$ & & & & & $\mathbf{n}(\%)$ & $\mathbf{n}(\%)$ & & & & \\
\hline \multirow[t]{2}{*}{$\begin{array}{l}\text { United } \\
\text { Kingdom }\end{array}$} & Coxib & $\begin{array}{c}128 \\
(41.7)\end{array}$ & $\begin{array}{c}24,722 \\
(50.6)\end{array}$ & 1.00 & & 1.00 & & $86(44.3)$ & $\begin{array}{l}14,835 \\
(51.1)\end{array}$ & 1.00 & & 1.00 & \\
\hline & nsNSAID+GPA \# & $\begin{array}{c}179 \\
(58.3)\end{array}$ & $\begin{array}{c}24,138 \\
(49.4)\end{array}$ & $\begin{array}{l}1.02 \\
(0.77- \\
1.36)\end{array}$ & 0.883 & $\begin{array}{c}1.05(0.77- \\
1.45)\end{array}$ & 0.742 & $\begin{array}{c}108 \\
(55.7)\end{array}$ & $\begin{array}{l}14,222 \\
(48.9)\end{array}$ & $\begin{array}{c}0.90(0.63- \\
1.29)\end{array}$ & 0.568 & $\begin{array}{c}1.20(0.80- \\
1.80)\end{array}$ & 0.375 \\
\hline \multirow{2}{*}{$\begin{array}{l}\text { The } \\
\text { Netherlands * }\end{array}$} & Coxib & $13(76.5)$ & $243(65.0)$ & 1.00 & & 1.00 & & $10(71.4)$ & $172(60.4)$ & 1.00 & & 1.00 & \\
\hline & nsNSAID+GPA \# & $4(23.5)$ & $131(35.0)$ & $\begin{array}{c}0.44 \\
(0.13- \\
1.48)\end{array}$ & 0.183 & $\begin{array}{c}0.54(0.16- \\
1.84)\end{array}$ & 0.323 & $4(28.6)$ & $113(39.6)$ & $\begin{array}{c}0.53(0.15- \\
1.88)\end{array}$ & 0.326 & $\begin{array}{c}0.63(0.18- \\
2.24)\end{array}$ & 0.478 \\
\hline \multirow[t]{2}{*}{ Italy } & Coxib & $44(59.5)$ & $6,201(74.4)$ & 1.00 & & 1.00 & & $6(35.3)$ & $1,124(64.6)$ & 1.00 & & 1.00 & \\
\hline & nsNSAID+GPA \# & $30(40.5)$ & $2,133(25.6)$ & $\begin{array}{c}1.22 \\
(0.69- \\
2.17)\end{array}$ & 0.500 & $\begin{array}{c}0.79(0.27- \\
2.35)\end{array}$ & 0.673 & $11(64.7)$ & $616(35.4)$ & $\begin{array}{c}2.85(0.92- \\
8.80)\end{array}$ & 0.069 & $\begin{array}{c}0.59(0.05- \\
6.55)\end{array}$ & 0.669 \\
\hline \multirow[t]{2}{*}{$\begin{array}{l}\text { Pooled on } \\
\text { patient level }\end{array}$} & Coxib & $\begin{array}{c}185 \\
(46.5)\end{array}$ & $\begin{array}{c}31,166 \\
(54.1)\end{array}$ & 1.00 & & 1.00 & & $\begin{array}{c}102 \\
(45.3)\end{array}$ & $\begin{array}{l}16,131 \\
(51.9)\end{array}$ & 1.00 & & 1.00 & \\
\hline & nsNSAID+GPA \# & $\begin{array}{c}213 \\
(53.5)\end{array}$ & $\begin{array}{c}26,402 \\
(45.9)\end{array}$ & $\begin{array}{l}1.01 \\
(0.79- \\
1.30)\end{array}$ & 0.918 & $\begin{array}{c}1.02(0.77- \\
1.37)\end{array}$ & 0.880 & $\begin{array}{c}123 \\
(54.7)\end{array}$ & $\begin{array}{l}14,951 \\
(48.1)\end{array}$ & $\begin{array}{c}0.96(0.69- \\
1.33)\end{array}$ & 0.800 & $\begin{array}{c}1.14(0.78- \\
1.65)\end{array}$ & 0.503 \\
\hline
\end{tabular}

Cases and controls are matched on age, gender and number of individual UGI risk factors.

*

For NL: adjusted model also includes use of antiplatelets.

${ }^{\dagger}$ Adjusted for dose of NSAID, length of NSAID episode and density of NSAID use within episode. Only subjects included with known dosage of NSAID (UK $80.2 \%$; NL 100\%; IT 35.3\%).

${ }^{\#}$ nsNSAID+GPA ( $\geq 80 \%$ adherence) 
Table 3

Risk factors for symptomatic UGI events (UGI bleeding and symptomatic ulcer) and UGI bleeding; stratified analyses on data pooled on patient level.

\begin{tabular}{|c|c|c|c|c|c|c|c|c|c|}
\hline & & \multicolumn{4}{|c|}{$\begin{array}{l}\text { Symptomatic UGI events (UGI bleeding and } \\
\text { symptomatic ulcer) }\end{array}$} & \multicolumn{4}{|c|}{ UGI bleeding } \\
\hline & & $\begin{array}{l}\text { Cases } \\
\text { n }(\%)\end{array}$ & $\underset{(95 \% \text { CI })}{\text { ORmatched }}$ & P-value & $\begin{array}{c}\text { P-value } \\
\text { Interaction } \\
\text { terms }\end{array}$ & $\begin{array}{l}\text { Cases } \\
\mathbf{n}(\%)\end{array}$ & $\underset{(95 \% \text { CI })}{\text { ORmatched }}$ & P-value & $\begin{array}{c}\text { P-value } \\
\text { Interaction } \\
\text { terms }\end{array}$ \\
\hline \multicolumn{10}{|l|}{$\begin{array}{l}\text { Individual UGI risk } \\
\text { factors: }\end{array}$} \\
\hline \multirow[t]{2}{*}{ Age $\geq 65 \mathrm{yrs}$} & Coxib & $151(48.7)$ & 1.00 & & & $91(47.9)$ & 1.00 & & \\
\hline & nsNSAID+GPA \# & $159(51.3)$ & $0.88(0.67-1.17)$ & 0.394 & & $99(52.1)$ & $0.88(0.62-1.26)$ & 0.488 & \\
\hline No prior UGI event & Coxib & $171(50.6)$ & 1.00 & & & $93(50.0)$ & 1.00 & & \\
\hline Prior UGI event & nsNSAID+GPA $\#$ & $46(76.7)$ & $1.73(0.81-3.70)$ & 0.159 & & $30(76.9)$ & $1.90(0.74-4.86)$ & 0.182 & \\
\hline \multirow[t]{2}{*}{ No use of antiplatelets } & Coxib & $120(44.4)$ & 1.00 & & & $59(41.0)$ & 1.00 & & \\
\hline & nsNSAID+GPA & $150(55.6)$ & $1.23(0.91-1.66)$ & 0.181 & $<0.001$ & $85(59.0)$ & $1.24(0.83-1.87)$ & 0.298 & 0.008 \\
\hline \multirow[t]{2}{*}{ Use of antiplatelets } & Coxib & $65(50.8)$ & 1.00 & & & $43(53.1)$ & 1.00 & & \\
\hline & nsNSAID+GPA \# & $63(49.2)$ & $0.69(0.44-1.08)$ & 0.108 & & $38(46.9)$ & $0.62(0.34-1.06)$ & 0.079 & \\
\hline \multirow[t]{2}{*}{$\begin{array}{l}\text { No use of } \\
\text { anticoagulants }\end{array}$} & Coxib & $182(47.5)$ & 1.00 & & & 99 (46.7) & 1.00 & & \\
\hline & nsNSAID+GPA $\#$ & $201(52.5)$ & $0.99(0.76-1.27)$ & 0.904 & 0.078 & $113(53.3)$ & $0.91(0.65-1.28)$ & 0.603 & 0.085 \\
\hline
\end{tabular}

\begin{tabular}{|c|c|c|c|c|c|c|c|c|c|}
\hline \multirow[b]{2}{*}{$\begin{array}{l}\text { Individual UGI risk } \\
\text { factors: }\end{array}$} & & \multicolumn{4}{|c|}{$\begin{array}{l}\text { Symptomatic UGI events (UGI bleeding and } \\
\text { symptomatic ulcer) }\end{array}$} & \multicolumn{4}{|c|}{ UGI bleeding } \\
\hline & & $\begin{array}{l}\text { Cases } \\
\mathbf{n}(\%)\end{array}$ & $\begin{array}{l}\text { ORmatched } \\
(95 \% \text { CI })\end{array}$ & $P$-value & $\begin{array}{l}\text { P-value } \\
\text { Interaction } \\
\text { terms }\end{array}$ & $\begin{array}{l}\text { Cases } \\
\mathbf{n}(\%)\end{array}$ & $\underset{(95 \% \text { CI })}{\text { ORmatched }}$ & P-value & $\begin{array}{c}\text { P-value } \\
\text { Interaction } \\
\text { terms }\end{array}$ \\
\hline \multirow[t]{2}{*}{$\begin{array}{l}\text { No use of } \\
\text { glucocorticoids }\end{array}$} & Coxib & $180(47.7)$ & 1.00 & & & 99 (46.5) & 1.00 & & \\
\hline & nsNSAID+GPA \# & $197(52.3)$ & $0.96(0.74-1.24)$ & 0.740 & 0.280 & $114(53.5)$ & $0.91(0.65-1.27)$ & 0.571 & 0.724 \\
\hline \multirow[t]{2}{*}{$\begin{array}{l}\text { Use of } \\
\text { glucocorticoids }\end{array}$} & Coxib & $5(23.8)$ & 1.00 & & & $3(25.0)$ & 1.00 & & \\
\hline & nsNSAID+GPA $\#$ & $16(76.2)$ & $\begin{array}{l}7.03(1.35- \\
36.45)\end{array}$ & 0.020 & & $9(75.0)$ & $\begin{array}{l}4.15(0.72- \\
24.01)\end{array}$ & 0.112 & \\
\hline $\begin{array}{l}\text { Use of } \\
\text { glucocorticoids \#\# }\end{array}$ & nsNSAID+GPA $\#$ & $16(76.2)$ & $\begin{array}{l}9.01(1.61- \\
50.50)\end{array}$ & 0.012 & & $9(75.0)$ & $\begin{array}{l}4.81(0.79- \\
29.20)\end{array}$ & 0.088 & \\
\hline \multirow[t]{2}{*}{$\begin{array}{l}\text { Before rofecoxib } \\
\text { withdrawal }{ }^{\dagger}\end{array}$} & Coxib & $162(62.5)$ & 1.00 & & & $91(64.1)$ & 1.00 & & \\
\hline & nsNSAID+GPA & $97(37.5)$ & $1.05(0.79-1.40)$ & 0.729 & 0.702 & $51(35.9)$ & $0.92(0.62-1.34)$ & 0.649 & 0.781 \\
\hline \multirow[t]{2}{*}{$\begin{array}{l}\text { After rofecoxib } \\
\text { withdrawal } \hbar\end{array}$} & Coxib & $23(16.5)$ & 1.00 & & & $11(13.3)$ & 1.00 & & \\
\hline & nsNSAID+GPA \# & $116(83.5)$ & $0.91(0.57-1.47)$ & 0.702 & & 72 (86.7) & $1.10(0.56-2.15)$ & 0.781 & \\
\hline
\end{tabular}

Matched on age, gender and number of individual UGI risk factors. 


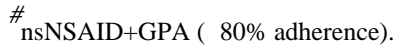

${ }^{\# \#}$ Adjusted for equipotent dosage of prednisone (low dosage: 5 to $10 \mathrm{mg} /$ day; moderate dosage: 10 to $20 \mathrm{mg} /$ day; high-dosage: $>20 \mathrm{mg} / \mathrm{day}$ )

'Rofecoxib withdrawal in September 2004, analysis until 2005.

Analysis from 2005 and subsequent years. 